\title{
Assessment of Learning Outcomes in the University Quality Management System
}

\author{
Nazina L.I.* \\ Department of Quality Management and Technology \\ of Aquatic Bioresources \\ State University of Engineering Technologies \\ Voronezh, Russia \\ e-mail nazina_lyudmila@mail.ru
}

Nikulcheva O.S.

Center for the Quality of Education and Employment of Graduates

Voronezh State University of Engineering Technologies Voronezh, Russia

e-mail strogonova.ox@yandex.ru

\section{Pribytkova O.V.}

Department of foreign languages

Voronezh State University of Engineering Technologies

Voronezh, Russia

e-mail lady.pribytkova@mail.ru

\begin{abstract}
The main criterion for increasing the competitiveness of educational institutions in the educational services market is the high level of training of graduates. In the context of the competency-based approach used to form a new model of graduates, their preparation for professional activity is important. To improve the efficiency of the educational process and the activities of the modern institution of higher education as a whole, to achieve quality goals and obtain results for stakeholders, it is rational to introduce quality management systems. When forming a model for assessing competencies, it is necessary to take into account that competencies are crosssubject in nature, require the use of a variety of assessment tools, methods and assessment scales. Requirements for the results of mastering the educational program are presented in the form of a set of competencies, distributed by type of professional activity for which graduates are preparing. Therefore, a competency assessment model using a generalized (integral) indicator is needed. The analysis of the results of competency formation for an individual student group revealed the most rational directions for future professional activity, timely adjustment of the learning process to increase the success of graduates in the labor market.
\end{abstract}

Keywords — quality management system, studying outcomes, competency assessment.

\section{INTRODUCTION}

The main criterion for increasing the competitiveness of educational institutions in the educational services market is the high level of training of graduates $[1,2]$. A modern approach that interprets learning outcomes not in the form of the amount of learned information, but as the ability of a person to

\author{
Kleymenova N.L. \\ Department of Quality Management and Technology \\ of Aquatic Bioresources \\ Voronezh State University of Engineering Technologies \\ Voronezh, Russia \\ e-mail klesha78@list.ru \\ Pegina A.N. \\ Department of Quality Management and Technology \\ of Aquatic Bioresources \\ Voronezh State University of Engineering Technologies \\ Voronezh, Russia \\ e-mail toriss@yandex.ru
}

Egorova G.N.

Department of Industrial Ecology, Equipment of Chemical and Petrochemical Industries

Voronezh State University of Engineering Technologies

Voronezh, Russia

e-mail egorovahp@gmail.com

adequately act on its base in various situations (including in situations of uncertainty), is a competency-based approach. It assumes the presence of a system for the formation of professional competence of graduates in the university.

Intra-university quality assurance systems are a prerequisite for the effective operation of a modern institution of higher education [3]. Currently, the main trend in the field of quality assurance in higher education is shifting the center of gravity from external quality control procedures of universities to internal assessment based on the requirements of international standards ISO 9000. The results of self-assessment are becoming, on the one hand, a mechanism for continuous internal improvement of the quality system, on the other - may be presented to external reviewers for spot checking. The introduction of a quality management system (QMS) in a university is a strategic decision that can help improve its performance and ensure a focus on sustainable development $[4,5]$.

The QMS includes actions by which the university sets its goals and defines processes and resources, manages the interacting processes and resources required to achieve quality goals and obtain results for interested parties (Fig. 1). Recommendations on the application of the requirements of ISO 9001 in the field of education are established by GOST R 52614.2-2006, which is fundamental in nature and establishes that the educational institution should [6, 7]. They determine the processes for organizing the educational process, conducting intermediate and final certification of students, manage these processes; constantly improve these processes and allocate the necessary resources. 


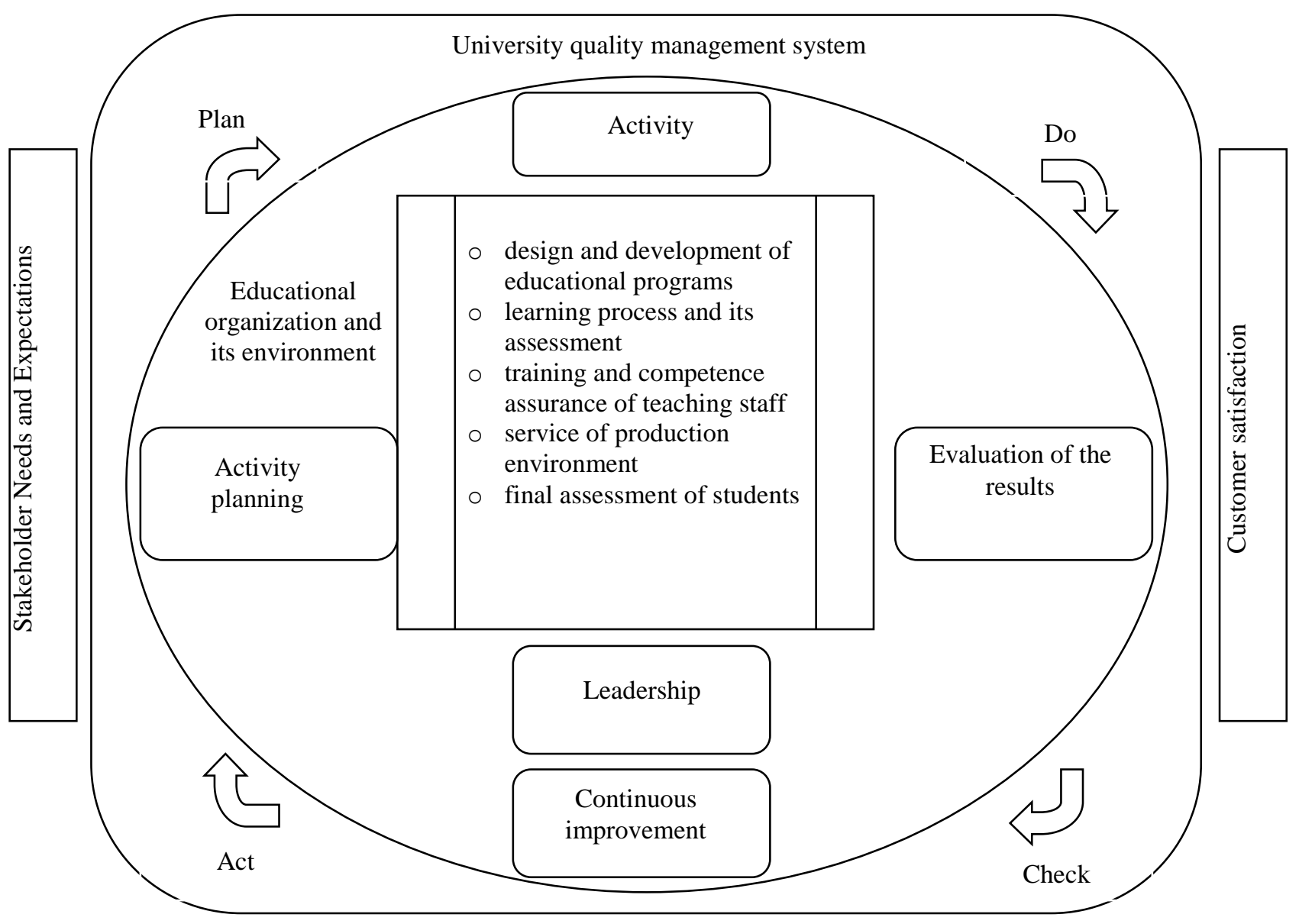

Fig. 1. Image of the structure of the QMS in the university in accordance with the PDCA cycle.

One of the principles of quality management [8] is a systematic approach that involves managing a set of interconnected and interacting elements of an educational organization to help increase the effectiveness and efficiency of the organization in achieving its goals in the field of quality. The process approach provides continuous management of all departments of the university [9]. At the same time, the process approach focuses on the process, not the end result. The principle of customer orientation guides the contractor in the implementation of his activities to focus on the needs of consumers of educational services.

One of the elements of self- assessment is the assessment of the learning outcomes of students [10]. The requirements for the quality of learning outcomes are presented in the Federal State Educational Standards of Higher Education (FSES HE), which are a combination of the general qualities of the human person, including his professional qualities, formed through the achievement of competencies. When assessing the level of mastering competencies, the following difficulties arise:

- competencies are of an interdisciplinary nature, therefore, for their assessment, it is necessary to use various assessment tools using various qualitative and quantitative scales;
- the wordings of competencies in FSES are general, imperfect, partially overlap.

In the process of implementing the educational program, the development of competencies is carried out by various technologies and training tools. At the same time, emphasis is placed on independent and scientific research, students' production practice, which requires the development of creative qualities, the integrated application of theoretical knowledge in practice, and independence in the organization of their activities.

Therefore, there is a need to develop modern assessment tools that will meet modern requirements for the quality of graduate training. Using the classical assessment on a fivepoint scale will not allow obtaining a reliable description of the success of graduates in future professional activities.

As an example, the content of the competency PC-3 from the standard of FSES HE for the training area 27.03.01 Standardization and metrology: "the ability to perform metrological support and technical control, use modern methods of measurement, control, testing and quality management". The formation of this competency is carried out in the course of studying various disciplines related to metrology, the use of modern technical means for control 
operations, and the study of modern methods of controlling the quality of products, processes, etc.

Therefore, the urgent task is to develop a technology for assessing the formation of a separate competency [11] and the competence of the graduate as a whole.

\section{METHODS AND MATERIALS}

The demand for graduates is primarily determined by their willingness to fulfill the tasks of professional activity corresponding to a certain area of professional activity (APA) [12].

FSES HE defines the requirements for the results of the mastering of an educational program (EP) by the types of professional activity for which graduates are trained $[13,14]$. Using the example of bachelor training in the direction 27.03.01 Standardization and metrology, the requirements for the results of mastering the program (Fig. 2) in the form of professional competencies grouped by type of professional activity are considered.

Competency is an integrated characteristic and is formed sequentially as part of the study of several disciplines and practices of EP $[15,16]$.

Moreover, initially, competence is formed at the threshold level - the student acquires knowledge, then at the advanced level - acquires skills in using the acquired knowledge, and finally, at a high level - develops skills for practical application of theoretical knowledge, acquires experience of their effective and creative use.

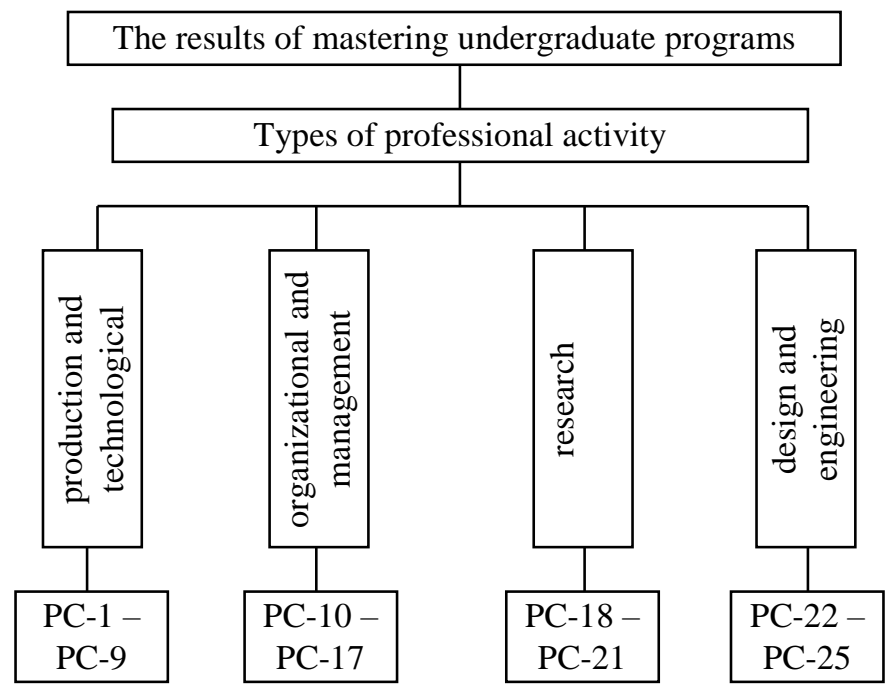

Fig. 2. Requirements for the results of mastering the undergraduate program by type of professional activity

Therefore, the competency assessment model is a function of several variables:

$$
q=f\left(x_{1}, x_{2}, \ldots, x_{k}\right),
$$

where $q$ - assessment of the formation of a single competency; $x_{1}, x_{2}, \ldots, x_{k}$ - factors characterizing the components of the competency.
Given the proposed structure of competency, $x_{1}$ is the assessment of disciplinary control (students' knowledge of a number of disciplines necessary for the formation of competency). $x_{2}$ is an assessment of multidisciplinary control (the formation of skills to apply knowledge in practice when students complete case studies, course projects and works, and individual tasks) when performing all types of practice, the ability to solve various problems during the graduate design, apply the basic principles and methods of the natural and mathematical sciences, and that the assessment of whether the student is able to effectively and creatively use the provisions and methods of the various sciences, and find their own decisions in the professional environment). $x_{3}$ is the assessment of the personal qualities of the graduate necessary for effective work individually, as well as a member of a team on interdisciplinary topics, etc.

To construct a mathematical model of competency assessment, you can use the polynomial model of the following form:

$$
q=b_{1} x_{1}+b_{2} x_{2}+\ldots=\sum_{i=1}^{n} b_{i} x_{i}
$$

where $b_{i}$ - weighting factor determined by expert methods.

The variables used to assess the level of competency are measured in various units of measurement (for example, grade for an exam, test result, rating score, self-assessment of personal qualities, etc.). To avoid the "dominance" of variables with a large scale of measurement, it is proposed to carry out a preliminary normalization of the initial variables. Regression coefficients in this expression characterize the contribution of each component to the resulting assessment.

The set of assessments of competencies for each area of professional activity (APA) can be assessed as the competence of students in this field. Consequently, the level of development of competence for each of the APA depends on a number of factors (competencies) and the insufficient level of development of any factor ultimately reduces the level of competence. When solving multicriteria problems of this kind, various methods of convolution of criteria into one generalized (integral) indicator are often used.

Methods for constructing a complex criterion are additive and multiplicative convolutions. Additive convolution is the sum of individual criteria, which is applied if there is the possibility of unlimited compensation of the values of some criteria at the expense of others.

$$
Q=\sum_{i=1}^{n} m_{i} q_{i},
$$

where $q_{i}$ - numerical value of the $\mathrm{i}$ indicator; $n$ - number of individual indicators; $m_{i}$ - corresponding weighting factors.

In cases where the influence of each parameter is significant, and we cannot ignore the values of at least one criterion, it is advisable to use a multiplicative convolution, since the additive convolution is insensitive to the extreme values of individual criteria. 


$$
Q=\prod_{i=1}^{n} q_{i}^{m_{i}} .
$$

In the case of applying the multiplicative convolution, if at least one of the parameters is zero, the entire convolution will give a zero result. To obtain a comprehensive assessment of the formation of a set of competencies for a specific APA, it is most rational to use multiplicative convolution.

\section{RESULTS}

The results of the calculation of competence in the production and technological (Fig. 3) and research (Fig. 4) areas of professional activity on the example of a group of students in the direction of 27.03.01 are presented in the form of laws of distribution of integral indicators.

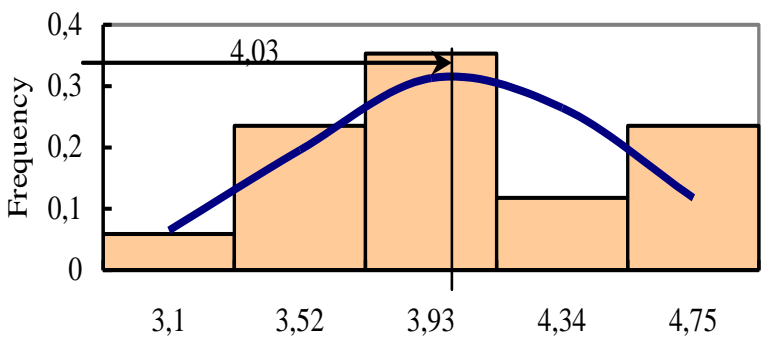

Formation assessment Qpr-tech

Fig. 3. A histogram of the distribution of assessments of the formation of competencies in the production and technological areas of professional activity for a student group

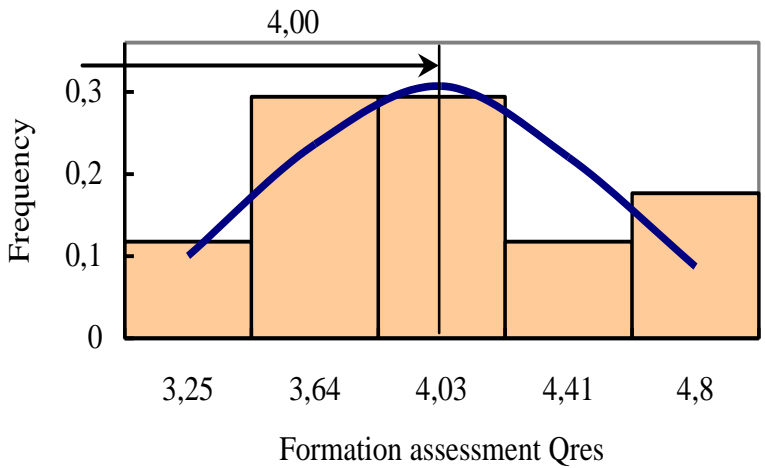

Fig. 4. The histogram of the distribution of assessments of the formation of competencies in the research area of professional activity for a student group

An analysis of the distribution diagrams made it possible to conclude that the distribution laws of these indicators are close to normal with the parameters: average $Q_{\text {pr-tech }}{ }^{\text {av }}=4,03$; standard deviation $\sigma_{\text {pr-tech }}=0,52 ;$ average $Q_{\text {res }}^{\text {av }}=4,00$; standard deviation $\sigma_{\text {res }}=0,50$. Testing the hypothesis of equality of averages at a significance level of 0.05 showed that the difference in the values of $Q_{\text {pr-tech }}{ }^{\text {av }}$ and $Q_{\text {res }}{ }^{\text {av }}$ is insignificant. Consequently, the level of development of competencies related to various APA is approximately equal. Graduates are prepared to solve professional problems in different fields of activity in the same way; they will be able to be successful at various enterprises and organizations, in production units and research laboratories.
The analysis of variance carried out on the results of the formation of competencies PC-1 - PC-9 showed that the variances and average values of estimates at the significance level of 0.05 differ insignificantly; intra-group variability is much greater than the variability between samples. This indicates that the variability of assessments of the formation of competencies within the student group is great.

An analysis of the correlation relationship between $Q_{\text {pr-tech }}$ and $Q_{\text {res }}$ has revealed a close direct relationship between the parameters (the linear correlation coefficient was 0.97).

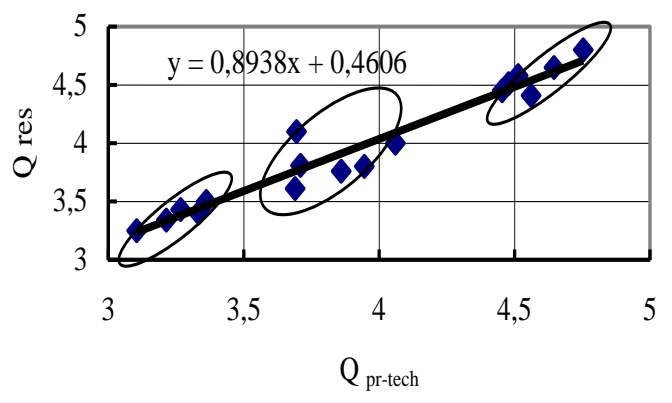

Fig. 5. The scatter chart for assessing the formation of competencies in the production and technological and research APA for the student group

In the scatter chart, sets of points corresponding to subgroups of students having similar levels of development are observed. This confirms the hypothesis that the formation of competencies is carried out at three levels - threshold, high and advanced. Corrective measures should be developed for students with a low level of knowledge, skills and possessions, aimed at improving the quality of the educational process, for example, by choosing the disciplines of the variable block (elective disciplines and electives), organizing the work of scientific creativity clubs, etc.

In order to improve the organization of the learning process, it is necessary to analyze the cause-effect relationships of the occurrence of "weaknesses" in the formation of competencies in order to identify key processes of interaction of the input and output parameters of the studied competencies. The reasons for the low level of competency formation can be represented in the form of Ishikawa diagram (Fig. 6).

To exclude the influence of the identified causes on the result, it is necessary:

a) to improve the system of ensuring the competence and awareness of scientific and pedagogical staff;

b) to improve existing and apply modern technologies of active and interactive learning;

c) to orient the content of training on the strategic direction of the development of engineering and technology, the needs of enterprises;

d) to expand the relationship between the university and potential employers, to involve research and production units of organizations and enterprises in the process of forming competencies;

e) to develop methods for continuous improvement and management of the educational process. 


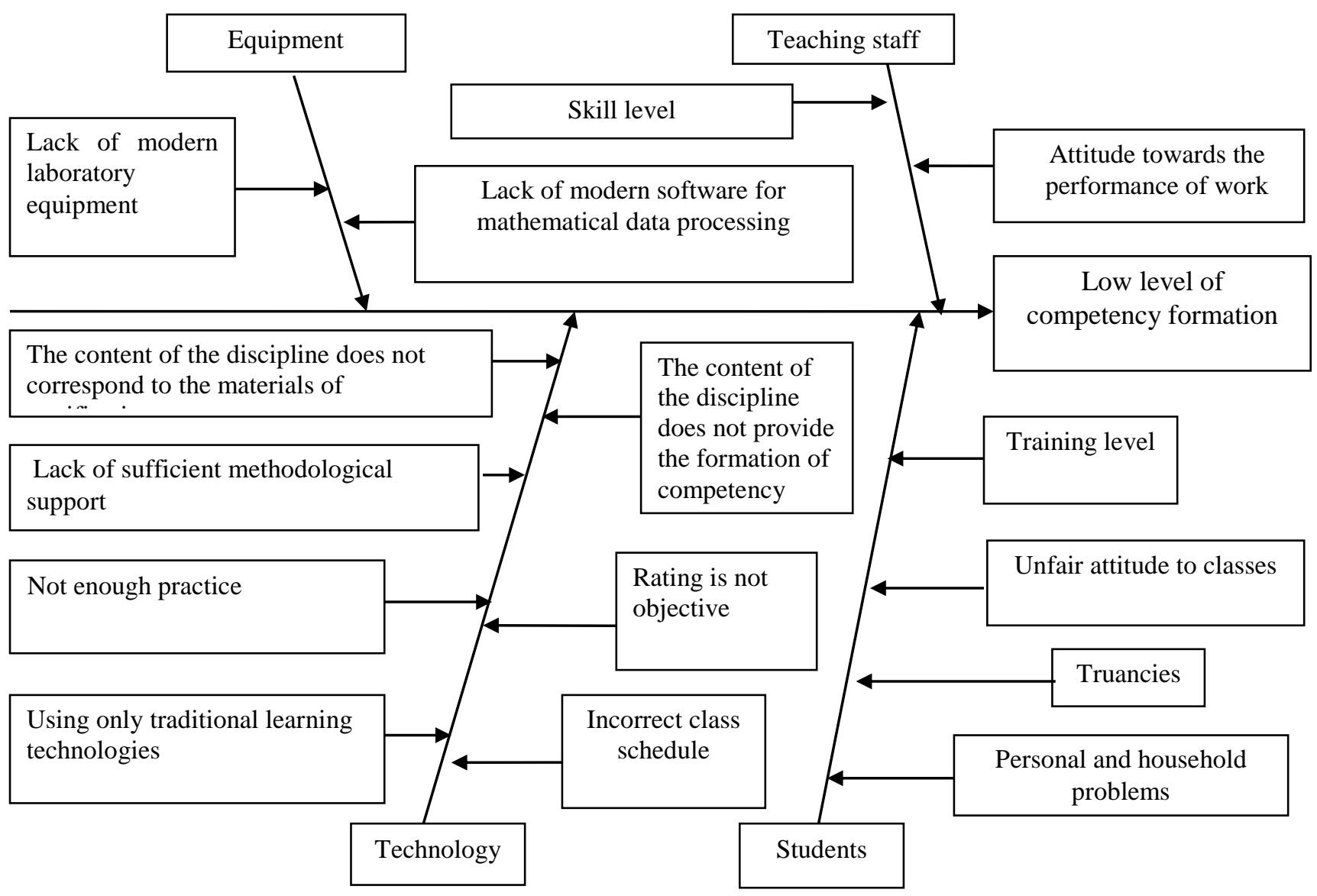

Fig. 6. Ishikawa diagram for analyzing the reasons for the low level of competency formation

\section{CONCLUSION}

In the context of competence approach used for the formation of a new model of graduates it is important to prepare them for professional activity.

To improve the efficiency of the educational process and the activities of the modern institution of higher education as a whole, to achieve quality goals and obtain results for stakeholders, it is rational to introduce quality management systems.

When forming a model for assessing competencies, it is necessary to take into account that competencies are interdisciplinary in nature, require the use of a variety of assessment tools, methods and assessment scales.

Requirements for the results of mastering the educational program are presented in the form of a set of competencies, distributed by type of professional activity for which graduates are trained. Therefore, a competency assessment model is needed using a generalized (integral) indicator.

An analysis of the results of competency formation for an individual student group revealed the most rational areas of future professional activity, timely adjustment of the learning process to increase the success of graduates in the labor market.

\section{References}

[1] N. Glushak, Y. Katkow, O. Glushak, E. Katkowa, N. Kovaleva, "Contemporary Economic Aspects of Education Quality Management at the University", Proc. - Soc. and Behavioral Sci., vol. 214, pp. 252-260, 2015.

[2] J. Langstrand, P. Cronemyr, B. Poksinska, "Practise what you preach: quality of education in education on quality" Total Quality Manag. \& Busin. Excellence, vol. 26, pp. 1202-1212, 2015, Retrieved from: https://doi.org/10.1080/14783363.2014.925290

[3] L. Moldovan, "Integration of Strategic Management and Quality Assurance in the Romanian Higher Education", Proc. - Soc. and Behavioral Sci., vol. 58, pp. 1458-1465, October 2012, Retrieved from: https://doi.org/10.1016/j.sbspro.2012.09.1132

[4] O.S. Nikulcheva, L.I. Nazina, A.A. Afanasev, "Management of educational programs on the base of standardization principles application", Proc. of Voronezh State Univer. of Engineer. Technol., vol. 1, pp. 243-248, 2016, Retrieved from: https://doi.org/10.20914/23101202-2016-1-243-248

[5] L. Moldovan, "Training Outcome Evaluation Model”, Procedia Technology 22, pp. 1184-1190, 2016 [9th Int. Conf. Interdisciplinarity in Engineering, INTER-ENG 2015, 8-9 October 2015, Tirgu Mures, Romania, 2015].

[6] GOST R 52614.2-2006. Guidelines for the use of GOST R ISO $9001-$ 2001 in the field of education. Moscow: Standartinform, 2007, 64 p.

[7] Teng Su-Hu, Yuan-Yuan Lu, Sheng-Chan Chiu, "Internal quality management instructors knowledge-training capabilities: an empirical study in Taiwan", Total Quality Manag. \& Busin. Excellence, vol. 26, pp. 284-297, 01 Jul 2015, Retrieved from: https://doi.org/10.1080/14783363.2013.809943 
[8] GOST R ISO 9001-2015, Quality Management Systems. Requirements, Moscow: Standartinform, 2018, 24 p.

[9] Juhani Anttila, Kari Jussila, "Universities and smart cities: the challenges to high quality", Total Quality Manag. \& Busin. Excellence, vol. 29, pp. 1058-1073, 17 Jun 2018, Retrieved from: https://doi.org/10.1080/14783363.2018.1486552

[10] M.J. Manatos, C.S. Sarrico, "The integration of quality management in higher education institutions: a systematic literature review", Total Quality Manag. \& Busin. Excellence, vol. 28, iss. 3-4, pp. 159-175, 2017, Retrieved from: https://doi.org/10.1080/14783363.2015.1050180

[11] V. Kalyuzhin, F. Karavaytsyev, V. Shchukina, "Complex competenceoriented tasks for the training of specialized professionals", E3S Web Conf. Business Technologies for Sustainable Urban Development, vol. 110, pp. 1-13, 2019 [Int. Sci. Conf. SPbWOSCE-2018], Retrieved from: https://doi.org/10.1051/e3sconf /20191100 SPbWOSCE-2018 21162116

[12] O.S. Nikulicheva, S.G. Tikhomirov, I.A. Khaustov, L.I. Nazina, "Assessment of Competence and Readiness of Graduates to Solve Professional Problems", Issues of modern sci. and pract. University.
V.I. Vernadsky, vol. 3, no. 69, pp. 155-165, 2018, Retrieved from: https://doi.org/10.17277/voprosy.2018.03.pp.155-165

[13] O.V. Romanovtseva, "The Competence Approach in Education", vol. 2, no 4, pp. 83-91, 2016, Retrieved from: https://doi.org/10.17922/2412 5466-2016-2-4-83-91

[14] S.S. Kunanbayeva, "Educational Paradigm: Implementation of the Competence-Based Approach to the Higher School System", Int. J. of Environmental and Sci. Ed., vol. 11, no. 18, pp. 12699-12710, 2016.

[15] N.A. Zaitseva, D.A. Kozlov, E.Y. Nikolskaya, "Evaluation of the Competencies of Graduates of Higher Educational Institutions, Engaged in the Training of Personnel for Tourism and Hospitality", Eurasian J. of Analyt. Chem., pp. 685-695, 2017, Retrieved from: https://doi.org/10.12973/ejac.2017.00202a

[16] A. Maiurova, L. Konopelko, Y. Kustikov, M. Kustikova, E. Bykovskaia, E. Tyurikova, "New tendencies in teaching measurement science in the higher education", J. of Phys.: Conf. Ser., vol. 1379, no. 1, pp. 1-5, 2019, Retrieved from: https://doi.org/10.1088/1742-6596/1379/1/012047 